\title{
Microbial Succession in Spontaneously Fermented Grape Must Before, During and After Stuck Fermentation
}

\author{
A. Ultee ${ }^{*}$, A. Wacker ${ }^{1}$, D. Kunz ${ }^{1}$, R. Löwenstein ${ }^{2}$, H. König ${ }^{1}$ \\ (1) Institute of Microbiology and Wine Research, Johannes Gutenberg University Mainz, Johann-Joachim-Becherweg 15, \\ 55128 Mainz, Germany \\ (2) Winery Heymann-Löwenstein, Bahnhofstrasse 10, 56333 Winningen, Germany
}

Submitted for publication: September 2012

Accepted for publication: March 2013

Key words: Must, stuck fermentation, spontaneous fermentation, microbial succession, yeasts, bacteria, qPCR, specific primers

\begin{abstract}
The microbial succession in spontaneously fermenting Riesling must was investigated from the beginning (pressing) until the end (sulphuring) of the fermentation in two harvest years (2008 and 2009) at a Moselle winery (Germany). In both years, the fermentation was interrupted by a stuck period. The length of the stuck period varied considerably (20 weeks in 2008 and one week in 2009). Different yeasts (Candida, Debaryomyces, Pichia, Hanseniaspora, Saccharomyces, Metschnikowia, Cryptococcus, Filobasidium and Rhodotorula) and bacteria (Gluconobacter, Asaia, Acetobacter, Oenococcus, Lactobacillus, Bacillus and Paenibacillus) were isolated successively by plating. The main fermenting organism was Saccharomyces uvarum. Specific primers were developed for $S$. uvarum, $H$. uvarum and $C$. boidinii, followed by the determination of the total cell counts with qPCR. The initial glucose concentration differed between the two years and was $116 \mathrm{~g} / \mathrm{L}$ in 2008 and $85.4 \mathrm{~g} / \mathrm{L}$ in 2009. Also, the fructose concentrations were different in both years $(114 \mathrm{~g} / \mathrm{L}$ in 2008 and $77.8 \mathrm{~g} / \mathrm{L}$ in 2009). The stuck period appeared when the glucose/fructose ratio was 0.34 and 0.12 respectively. The microbiota changed during the stuck period.
\end{abstract}

\section{INTRODUCTION}

During the alcoholic fermentation of grape must, sugars like glucose and fructose are converted to mainly ethanol and $\mathrm{CO}_{2}$. An often observed phenomenon during spontaneous fermentation is a sluggish or even a stuck fermentation. Different factors have an influence on this situation, e.g. viticultural treatments, harvest conditions, $\mathrm{pH}$, temperature, $\mathrm{O}_{2}$ concentration, nutrient deficiencies (nitrogen, sugar, vitamins, minerals), glucose/fructose ratio and inhibitory substances (fungicides, killer toxins) (Gafner \& Schütz, 1996; Alexandre \& Charpentier, 1998; Malherbe et al., 2007; Berthels et al., 2008). Although these factors are known, the problem cannot always be solved by the application of classical measures (e.g. temperature adjustment, the addition of nutrients or novel starter cultures). In addition, winemakers of the upper quality segment avoid these procedures. In their opinion, these measurements could change the characteristic sensory profiles of the individual wines. Therefore, the so far unknown causes have to be studied in more detail. Interactions between the organisms possibly play an important role, but very little is known regarding these interactions. For a better understanding of the interactions between the different microorganisms, knowledge about the succession of the microbiota in the fermenting must is important. Saccharomyces cerevisiae was assigned to play a main role during the fermentation, although other organisms have been isolated from grape must (Du Toit \& Lambrechts, 2002; Lopez et al., 2003; Nisioutou et al., 2007; Renouf et al., 2007; Lopandic et al., 2008). In general, non-Saccharomyces yeasts start the fermentation (high sugar concentration) and are substituted by $S$. cerevisiae strains when the alcohol concentration increases. Many investigations describe the presence of organisms in the grape must, although most studies were restricted to one group of organisms (e.g. yeasts, lactic acid bacteria, acetic acid bacteria) and/or to one stage during the fermentation (Cocolin et al., 2000; Mills et al., 2002; Bae et al., 2006; Renouf et al., 2007). To our knowledge, no studies describe the microbial (yeasts and bacteria) succession in stuck grape must over several months. In contrast to other studies, this has been investigated in the present study from pressing (October) until the end of the fermentation (June and January, respectively). Spontaneously fermented grape must (Riesling) from a Moselle winery in Germany was studied during two harvest periods in which stuck fermentation occurred. Total counts were measured for S. uvarum, $H$. uvarum and $C$. boidinii. In addition, some other factors $(\mathrm{pH}$, glucose, fructose, acetate, ethanol) were measured to obtain more information about the circumstances under which the must became stuck. 


\section{MATERIALS AND METHODS}

\section{Sampling}

Riesling must samples were collected at a Moselle winery (Winningen, Germany) during the whole fermentation period (from pressing until $\mathrm{SO}_{2}$ addition at the end of the alcoholic fermentation). In the first year, this period was from October 2008 until June 2009, and in the second year it was from October 2009 until January 2010. Samples were collected from one barrel at one position (from a tap at the lower part of the barrel). The must was fermented spontaneously at 12 to $13^{\circ} \mathrm{C}$ in a $3000 \mathrm{~L}$ stainless steel tank. At day 80 in 2008 , during the stuck period, the "same" must from a parallel (also stuck) barrel was combined with our must for practical reasons of the winemaker.

Samples $(45 \mathrm{~mL})$ for the isolation of microorganisms were taken from the barrel every two weeks during the entire fermentation period and once a month during the stuck period. After sampling, the must samples were transported to the laboratory in a cooling bag and processed directly after arriving at the laboratory. Samples for the glucose, fructose, acetate and ethanol measurements were taken every two or three days and directly frozen at $-18^{\circ} \mathrm{C}$ until used further.

\section{Isolation of bacteria and yeasts}

Bacteria and yeasts were isolated from the must by plating serial dilutions of must samples on different nutrient media. The media were chosen after preliminary work at the same winery. All media, except tomato juice medium, were adjusted to $1 \mathrm{~L}$ with $\mathrm{H}_{2} \mathrm{O}$.

\section{Tryptic soya agar (TSA) for bacteria:}

$15.0 \mathrm{~g}$ tryptone, $5.0 \mathrm{~g}$ soya peptone, $5.0 \mathrm{~g} \mathrm{NaCl}, 0.67 \mathrm{~g}$ potassium sorbate, $12.0 \mathrm{~g}$ agar.

Tomato juice medium (TSM) for lactic acid bacteria:

$5.0 \mathrm{~g}$ peptone, $5.0 \mathrm{~g}$ yeast extract, $20.0 \mathrm{~g}$ tryptone, $5.0 \mathrm{~g}$ glucose, $5.0 \mathrm{~g}$ fructose, $3.0 \mathrm{~g}$ citric acid, $1.0 \mathrm{~g}$ Tween-80, $0.5 \mathrm{~g} \mathrm{MgSO}_{4} \cdot 7 \mathrm{H}_{2} \mathrm{O}, 0.67 \mathrm{~g}$ potassium sorbate, and $1000 \mathrm{~mL}$ $\mathrm{H}_{2} \mathrm{O}$. Finally, $333 \mathrm{ml}$ of centrifuged tomato juice and $16.0 \mathrm{~g}$ agar were added after the $\mathrm{pH}$ of the medium was adjusted to 6.0 .

Yeast extract peptone mannitol agar (YPM) for acetic acid bacteria:

$5.0 \mathrm{~g}$ yeast extract, $3.0 \mathrm{~g}$ peptone, $25.0 \mathrm{~g}$ mannitol, $2.0 \mathrm{~g}$ $\mathrm{CaCO}_{3}, 12.0 \mathrm{~g}$ agar.

Man-Rogosa-Sharp agar (MRS) for lactic acid bacteria: $10.0 \mathrm{~g}$ peptone, 10.0 meat extract, $5.0 \mathrm{~g}$ yeast extract, $20.0 \mathrm{~g}$ glucose, $2.0 \mathrm{~g} \mathrm{~K}_{2} \mathrm{HPO}_{4}, 2.0 \mathrm{~g}$ diammonium hydrogen citrate, $5.0 \mathrm{~g}$ sodium acetate, $0.2 \mathrm{~g} \mathrm{MgSO}_{4} \cdot 7 \mathrm{H}_{2} \mathrm{O}, 1.0 \mathrm{~g}$ Tween- 80 , $0.05 \mathrm{~g} \mathrm{MnSO}_{4} \cdot \mathrm{H}_{2} \mathrm{O}, 0.67 \mathrm{~g}$ potassium sorbate, $12.0 \mathrm{~g}$ agar.

Yeast extract peptone agar (YEP) for yeasts:

$10.0 \mathrm{~g}$ yeast extract, $10.0 \mathrm{~g}$ peptone, $5.0 \mathrm{~g} \mathrm{NaCl}, 12.0 \mathrm{~g}$ agar.

Glucose-peptone-yeast extract agar (GPYA) for yeasts:

$40.0 \mathrm{~g}$ glucose, $5.0 \mathrm{~g}$ peptone, $5.0 \mathrm{~g}$ yeast extract, $15.0 \mathrm{~g}$ agar.

Potato dextrose agar (PDA) for yeasts:

$26.5 \mathrm{~g}$ potato dextrose bouillon (Roth, Karlsruhe, Germany), $12.0 \mathrm{~g}$ agar.

Glucose-yeast extract-peptone agar (GYP) for yeasts: $10.0 \mathrm{~g}$ yeast extract, $20.0 \mathrm{~g}$ peptone, $20.0 \mathrm{~g}$ glucose, $15.0 \mathrm{~g}$ agar.
Tomato juice agar, YPM and TSA were supplemented with $20.0 \mathrm{mg} / \mathrm{L}$ cycloheximide after autoclaving to prevent the growth of yeasts, and YPM was supplemented with $20 \mathrm{~mL} / \mathrm{L}$ ethanol.

After incubation at $20^{\circ} \mathrm{C}$, morphologically different colonies were picked and transferred to fresh agar plates. This last step was repeated several times to obtain pure cultures consisting of one species. At least three colonies of the same morphology per medium were picked. To isolate Oenococcus oeni species, $1 \mathrm{~mL}$ must was incubated in 10 $\mathrm{mL}$ tomato juice medium (without agar) and incubated at $20^{\circ} \mathrm{C}$.

DNA isolation and amplification from cultured strains Bacterial genomic DNA was extracted from the cells with InstaGene ${ }^{\mathrm{TM}}$ Matrix (Bio-Rad Laboratories, Hercules, CA, USA), as described by Ultee et al. (2004). One colony was suspended in $100 \mu \mathrm{L}$ InstaGene ${ }^{\mathrm{TM}}$ Matrix. After incubation for $20 \mathrm{~min}$ at $56^{\circ} \mathrm{C}$ (under shaking), the suspension was vortexed for $10 \mathrm{~s}$, incubated for $10 \mathrm{~min}$ at $99^{\circ} \mathrm{C}$ (under shaking) and vortexed for $10 \mathrm{~s}$. The samples were centrifuged (1 min, 16 $100 \mathrm{~g}$ ) and the supernatant, containing the DNA, was stored at $-20^{\circ} \mathrm{C}$ until further use. The $16 \mathrm{~S}$ rDNA of the bacteria was amplified by PCR using the universal primers Eubak5 (AGA GTT TGA TCM TGG CT) and C1392R (CCA CGG GCG GTG TGT AC). The PCR was performed in a thermocycler (Techgene; Labtech, Burkhardtsdorf, Germany). The thermal profile consisted of one cycle of $5 \mathrm{~min}$ at $95^{\circ} \mathrm{C}, 1.5 \mathrm{~min}$ at $57^{\circ} \mathrm{C}$ and $2 \mathrm{~min}$ at $72^{\circ} \mathrm{C}$, followed by 30 cycles of $1 \mathrm{~min}$ at $95^{\circ} \mathrm{C}, 1.5 \mathrm{~min}$ at $57^{\circ} \mathrm{C}$ and $2 \mathrm{~min}$ at $72^{\circ} \mathrm{C}$, and a final step of $10 \mathrm{~min}$ at $72^{\circ} \mathrm{C}$. The PCR products were checked on a $1 \%$ agarose gel $(100 \mathrm{~V})$ and purified with a QIAquick PCR purification kit (Qiagen, Hilden, Germany).

The genomic DNA of pure yeast cultures was isolated and amplified as described for the bacteria, but with the addition of $10 \mu \mathrm{L}$ lyticase $(3 \mathrm{U} / \mu \mathrm{L})$ to the InstaGene ${ }^{\mathrm{TM}}$ Matrix to perforate the yeast cell walls. For the DNA amplification, ITS4 (TCC TCC GCT TAT TGA TAT GC) and ITS5 (GGA AGT AAA AGT CGT AAC AAG G) primers were used to amplify the ITS1-5.8S-ITS2 region of the rDNA gene. The annealing temperature during the polymerase chain reaction was $54^{\circ} \mathrm{C}$.

\section{Restriction analysis}

To retrieve information about the systematic strain assignment, a restriction fragment length analysis of the amplified rDNA was carried out. The rDNA of isolated bacterial strains was digested (one enzyme per reaction) with $B s u$ RI (5'-GG^CC-3') and HpaII (5'- $\mathrm{C}^{\wedge} \mathrm{CGG}-3$ '), and the yeasts' rDNA and ITS DNA with $H$ haI (5'-GC' GC-3'), HaeIII (5'-GG^CC-3') and Hinfl (5'-G^ANTC-3'). Two microlitres of DNA was incubated with $1 \mu \mathrm{L} 10 \mathrm{x}$ restriction buffer (MBI-Fermentas, St Leon-Roth, Germany), $6 \mu \mathrm{L}$ sterile double deionised water and $1 \mu \mathrm{L}$ enzyme $(10 \mathrm{U} / \mu \mathrm{L})$ (MBI-Fermentas, St. Leon-Rot, Germany) for at least $5 \mathrm{~h}$ (BsuRI and HpaII), respectively, and $20 \mathrm{~min}$ (HhaI, HaeIII, Hinfl) at $37^{\circ} \mathrm{C}$. The restricted DNA was separated on a $2 \%$ agarose gel $(60 \mathrm{~V})$ and, depending on the restriction pattern, the strains were divided into groups. The rDNA of at least one strain of every group was sequenced by Eurofins MWG Operon (Ebersberg, Germany). 


\section{Identification}

After sequencing of the rDNA (16S or 5.8S and ITS region) of the different strains, the obtained nucleotide sequences were compared with the nucleotide sequences of the identified strains in the NCBI database (http://www.ncbi. nlm.nih.gov) using blastn. Not all sequences could be clearly assigned to a certain species. Consequently, the rDNA from strain A115 (Lactobacillus casei/Lactobacillus rhamnosus/ Lactobacillus paracasei subsp. paracasei) was also amplified with specific primers for L. casei, L. rhamnosus and L. paracasei, as described by Ward and Timmins (1999). Strain w84.23 (Lactobacillus buchneri/Lactobacillus parakeferi) was identified by its sugar metabolism. Cells were washed with growth medium (1\% peptone, $1 \%$ yeast extract) and incubated in $5 \mathrm{~mL}$ growth medium to which 5 $\mathrm{mL}(0.02 \mathrm{~g} / \mathrm{mL})$ of different sugars (arabinose, galactose, melezitose, raffinose, saccharose, xylose and glucose) had been added. The physiological features were compared with distinguishing data in Bergey's manual of systematic bacteriology (Hammes \& Hertel, 2009). The identification of the strain was verified by a specific amplified polymorphic DNA (SAPD)-PCR as described by Pfannebecker (2003).

\section{Quantitative determination of selected strains Primer development}

To obtain information about the total counts of Saccharomyces uvarum, Hanseniaspora uvarum and Candida boidinii, specific primers were developed (Table 2), as described by Rozen and Skaletsky (2000). Primer specificity was firstly checked by NCBI blasts (http://www.ncbi.nlm.nih.gov). Unintended self-complimentary and heterodimers were checked as described by Kibbe (2007) and Owczarzy et al. (2008). In addition, the developed primers were checked for their specificity to a variety of wine yeasts and bacteria from our institute's strain collection in a PCR, as described under "DNA isolation and amplification from cultured strains". Finally, PCR was carried out with the total DNA isolated from the must and with the DNA isolated from the single cultures previously isolated from the must. PCR purification was followed by a restriction digestion, as described under "Restriction analysis". The obtained pattern of the must sample was compared with the pattern of the previously isolated single cultures.

\section{Quantitative PCR (qPCR)}

After the development of specific primers, selected species in the must samples were quantified. DNA was isolated from different must samples from 2008 and 2009 with the Qiagen DNA Blood and Tissue Kit (Qiagen, Hilden, Germany). To be able to calculate cell numbers from the obtained cycle threshold value $(\mathrm{Ct})$ values, fresh cultures (grown in GYP medium) were counted with a Blaubrand $\AA$ (Brand $\mathrm{GmbH}+$ Co KG, Wertheim, Germany) counting chamber. After the preparation of serial dilutions, the DNA of these cultures was isolated with a Qiagen DNA Blood and Tissue Kit (Qiagen, Hilden, Germany), and the $\mathrm{Ct}$ values were measured in qPCR.

qPCR was performed in a Mastercycler ${ }^{\circledR}$ ep realplex (Eppendorf, Hamburg, Germany). Each tube contained $1 \mu \mathrm{L}$ template, $0.5 \mu \mathrm{L}$ of each primer $(0.2 \mathrm{pmol} / \mathrm{L}), 9 \mu \mathrm{L}$
RealMasterMix SYBR ROX (5 PRIME GmbH, Hamburg, Germany) and $9 \mu \mathrm{L} \mathrm{H}_{2} \mathrm{O}$. The initial step was $2 \mathrm{~min}$ at $95^{\circ} \mathrm{C}$, followed by 40 cycles of $20 \mathrm{~s}$ at $95^{\circ} \mathrm{C}, 20 \mathrm{~s}$ at $60^{\circ} \mathrm{C}$ and $20 \mathrm{~s}$ at $68^{\circ} \mathrm{C}$. The final elongation was $15 \mathrm{~s}$ at $68^{\circ} \mathrm{C}$, with a final denaturation for $15 \mathrm{~s}$ at $95^{\circ} \mathrm{C}$. The fluorescence $(520 \mathrm{~nm})$ was measured after every cycle. The $\mathrm{Ct}$ value was measured at a fluorescence of 92 (a.u.). All samples were measured in duplicate. The efficiency coefficient was calculated as described by Higuchi et al. (1993).

\section{Determination of selected must contents}

Must samples $(1 \mathrm{~mL})$ were centrifuged (5 min, 16100 $g$ ) and the supernatant was diluted (1- to 40-fold) with double deionised water, depending on the concentration of the substances. Glucose, fructose, acetate and ethanol concentrations were measured using an HPLC system: Shimadzu DIL-10ADVP auto injector (Shimadzu, Kyoto, Japan), Shimadzu LC-6A pump, Shimadzu SCL-6B system controller, refractive index detector 156 (Beckman, Krefeld, Germany); column heater ERC Gecko 2000 (Gynkotek HPLC, Germany); HPLC column: HPX 87H 300 x 8,8 mm (Biorad, München, Germany) connected with a precolumn of the same packing. Mobile phase: $6.5 \mathrm{mmol} / \mathrm{L} \mathrm{H}_{2} \mathrm{SO}_{4}$; oven temperature: $65^{\circ} \mathrm{C}$; flow rate: $0.6 \mathrm{~mL} / \mathrm{mL}$; injection volume: $5 \mu \mathrm{L}$.

\section{Chemicals}

All primers were purchased from Eurofins MWG Operon (Ebersberg, Germany), and the Taq polymerase and nucleotides from PeqLab (Erlangen, Germany).

\section{RESULTS \\ Isolation and identification}

The fermentation period (from pressing until sulphuring) was from October until June (240 days) in 2008 and from October until January (105 days) in 2009. Fermentation became stuck (no visible $\mathrm{CO}_{2}$ production in the barrel) in both periods, although the length of the stuck fermentation differed considerably (day 45 to 184 in 2008; day 41 to 48 in 2009).

\section{Yeasts}

During the fermentation, many different yeasts and bacteria could be isolated successively (Table 1). The yeast strains that were isolated in 2008 belonged to the Saccharomycetales and were represented by mitosporic Saccharomycetales (Candida), Saccharomycetaceae (Debaryomyces, Pichia and Saccharomyces), Saccharomycodaceae (Hanseniaspora, "Kloeckera lindneri") and Metschnikowiaceae (Metschnikowia). At the beginning of the fermentation, Candida oleophila, Candida zemplinina, Pichia kluyveri, Hanseniaspora uvarum and Metschnikowia pulcherrima were isolated. The main fermenting organism, Saccharomyces uvarum, was isolated from day 24 until the end of the fermentation in June. Candida boidinii could be detected from day 80 until the end, and Candida friedrichii, Debaryomyces hansenii and Pichia membranifaciens appeared at day 148 and day 240 respectively. In contrast, Candida friedrichii was isolated at the beginning of the fermentation period in 2009, and some other species (Saccharomyces paradoxus, 


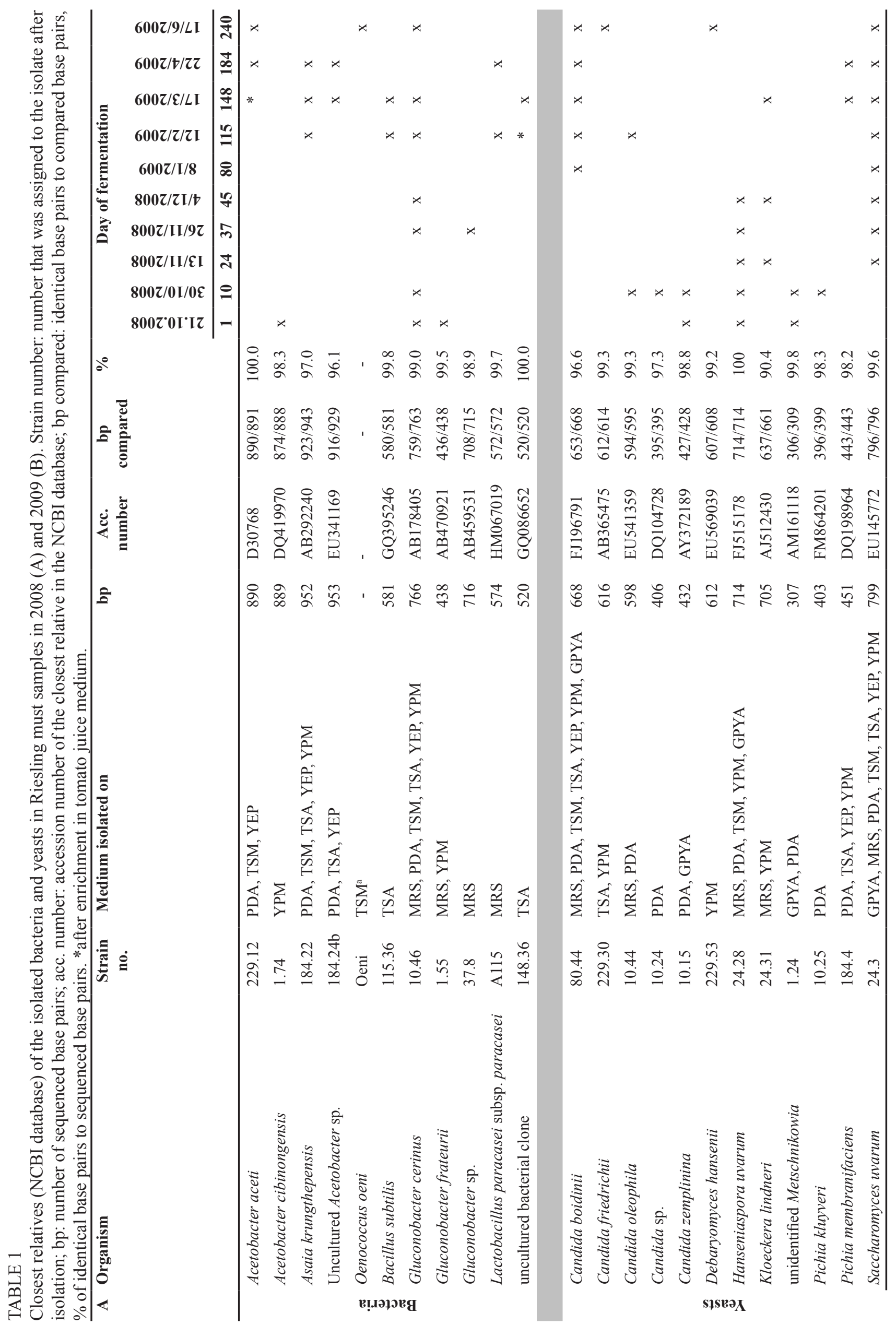




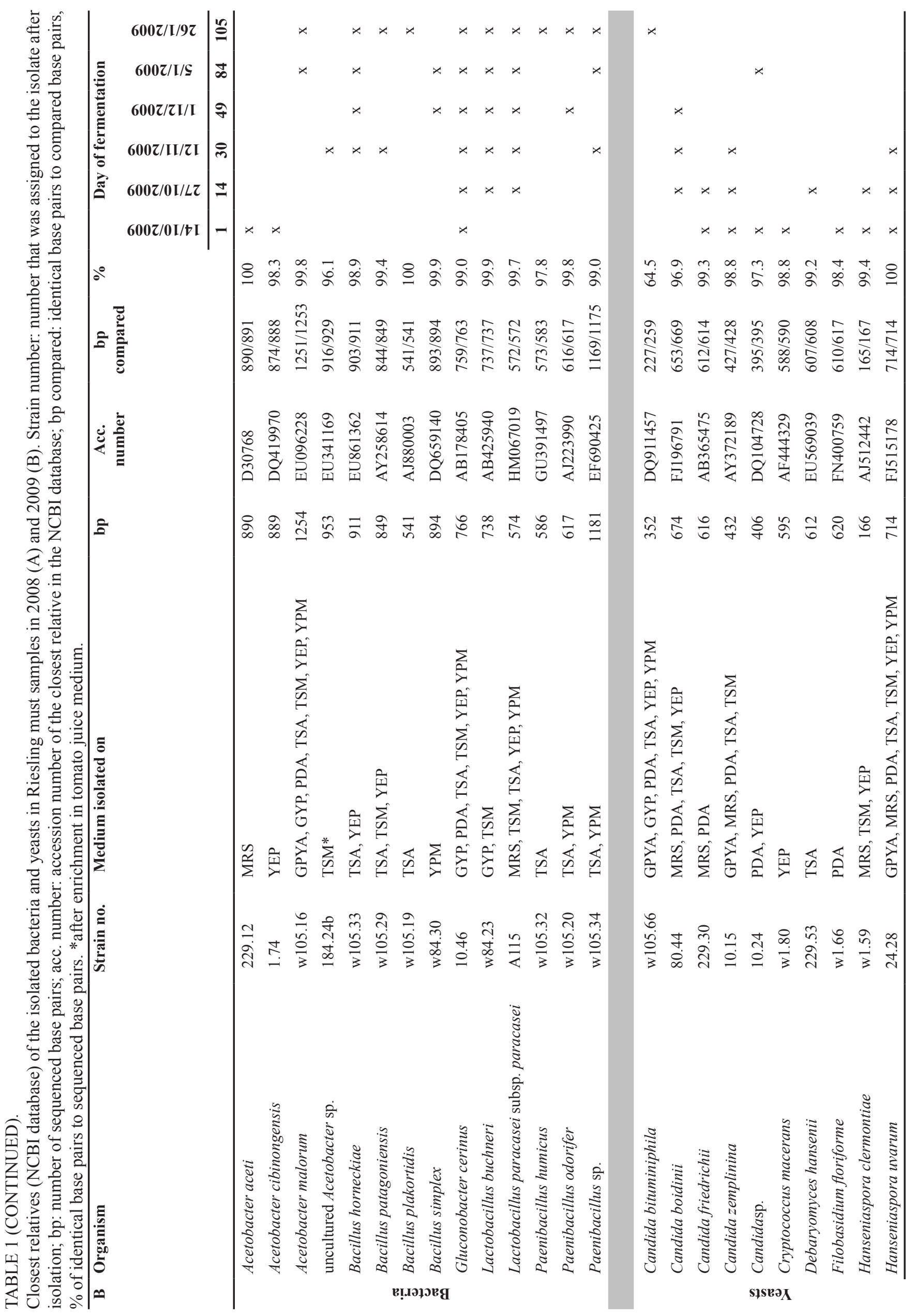




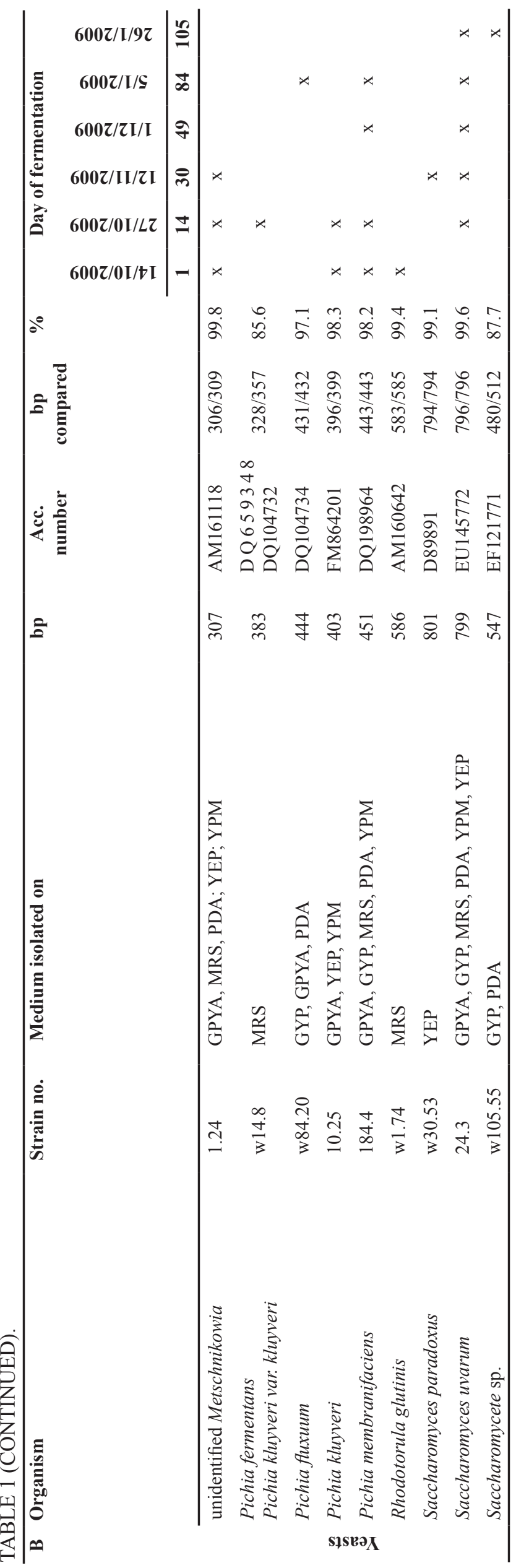

Hanseniaspora clermontiae, Pichia fluxum and the Basidiomycetes Crypotococcus macerans, Filobasidium floriforme and Rhodotorula glutinis) were only isolated in 2009. One yeast in 2008 (strain 24.31) and three yeasts in 2009 (strains w105.66, w14.8 and w105.55) could not be assigned to the species level.

\section{Bacteria}

In 2008, the isolated bacterial species belonged to two main groups: Proteobacteria and Firmicutes. The Proteobacteriaceae could be assigned to three genera, namely Gluconobacter, Asaia and Acetobacter. The Firmicutes group was represented by Lactobacillaceae (Lactobacillus and Oenococcus) and Bacillaceae (Bacillus). Gluconobacter cerinus could be isolated during the whole fermentation period, Acetobacter cibinongensis and Gluconobacter frateurii only at day 1, Gluconobacter sp. at day 37 , and the other bacteria during the stuck period until the end of the fermentation. In 2009, Lactobacillus buchneri and Acetobacter malorum were also isolated, but Gluconobacter frateurii, Asaia krungthepensis and Oenococcus oeni were not found. Interestingly, Acetobacter acet $i$ was isolated at the end (from day 148) of the fermentation period in 2008, but at the beginning of the fermentation (day 1 only) in 2009 . In addition, different species of the families Bacillaceae and Paenibacillaceae were isolated in 2009. However, they were isolated only very rarely (maximally twice at one sampling period) and they could not grow in the must after isolation (data not shown).

\section{Quantitative determination of $S$. uvarum, $H$. uvarum and} C. boidinii

Total counts of S. uvarum and H. uvarum were followed by qPCR (Fig. 1). These two strains were chosen as they are known to be present at higher numbers during (early) fermentation (Bisson \& Joseph, 2009; Dittrich \& Grossmann, 2011). S. uvarum was the main fermenting organism in this study. Since Candida boidinii was detected by plating in 2008 from day 80 (stuck period) until the end of the fermentation, its cell counts were investigated as well.

In 2008 (Fig 1A), S. uvarum total counts increased rapidly after the beginning of the fermentation, from $5.6 \mathrm{x}$ $10^{2}$ cells $/ \mathrm{mL}$ to $1.7 \times 10^{7}$ cells $/ \mathrm{mL}$ at day 37 . Towards the end of the fermentation, total counts were increased further to $8.7 \times 10^{7}$ cells $/ \mathrm{mL}$. H. uvarum was present at $3.6 \times 10^{4}$ cells $/ \mathrm{mL}$ at the beginning of the fermentation, increased to $5.5 \times 10^{7}$ cells $/ \mathrm{mL}$ at day 37 , and then gradually decreased to $1.1 \times 10^{6}$ cells $/ \mathrm{mL}$ at day 80 . The final total counts at the end of the fermentation were $7.0 \times 10^{5}$ cells $/ \mathrm{mL}$. C. boidinii counts increased slowly in the first phase of the fermentation, increased to $2.1 \times 10^{4}$ cells $/ \mathrm{mL}$ during the stuck fermentation (day 115), and decreased to the end of the fermentation. Interestingly, all counts had increased by day 115, although no visible $\mathrm{CO}_{2}$ production was detected at the top of the vessel.

In 2009 (Fig 1B), counts of S. uvarum (77 cells $/ \mathrm{mL}$ ) were lower compared to 2008 at the beginning of the fermentation. As in 2008, highest counts at the beginning were for $H$. uvarum $\left(1.7 \times 10^{7}\right.$ cells $/ \mathrm{mL}$ in 2009$)$, although these counts did not increase further. Again, S. uvarum counts increased rapidly after the fermentation started and were $3.0 \times 10^{7}$ 
TABLE 2

Specific primers for the quantification of S. uvarum, H. uvarum and C. boidinii in must samples.

\begin{tabular}{|c|c|c|c|c|c|c|}
\hline Organism & Primer & Sequence & Length & $\mathrm{T}_{\mathrm{m}}\left({ }^{\circ} \mathrm{C}\right)$ & $\begin{array}{l}\text { Product } \\
\text { size }\end{array}$ & Comments \\
\hline \multirow{2}{*}{$\begin{array}{l}\text { Saccharomyces } \\
\text { uvarum } \\
(24.3)\end{array}$} & CSP2-F & ATCGAATCTTTGAACGCACATTG & 23 & 57.1 & 173 & \multirow[t]{6}{*}{$\begin{array}{l}\text { modified from Hierro } \\
\text { et al. }(2007)\end{array}$} \\
\hline & SCER-R & CGCAGAGAAACCTCTCTTTGGA & 22 & 60.3 & & \\
\hline $\begin{array}{l}\text { Hanseniaspora } \\
\text { uvarum }\end{array}$ & Hans-F2 & GCACATTGCGCCCTTGAGCAT & 21 & 61.8 & 173 & \\
\hline$(37.4)$ & Hans-R2 & ATCACAGCGAGAACAGCGTCTC & 22 & 62.1 & & \\
\hline Candida boidinii & $80.44-1 \mathrm{~F}$ & GTGGTGATGAACGACACTTTCG & 22 & 60.3 & 135 & \\
\hline$(80.44)$ & $80.44-1 \mathrm{R}$ & AGGCAAAGCCCATAACTCCAAC & 22 & 60.3 & & \\
\hline
\end{tabular}

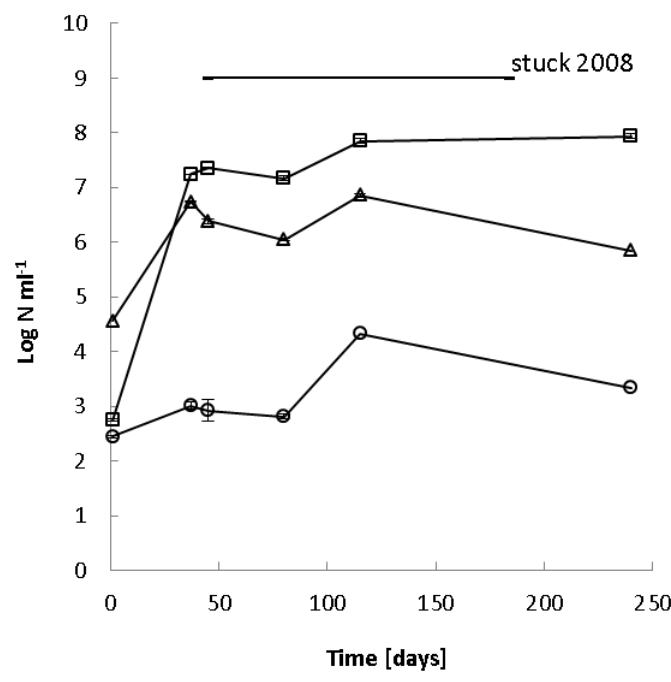

A

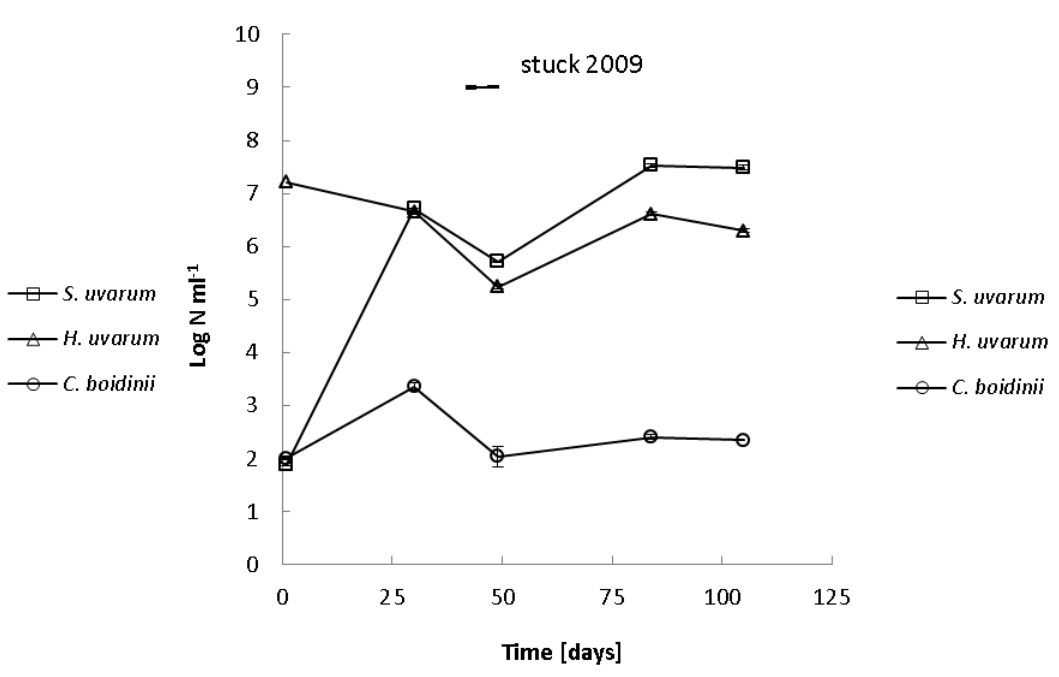

$\mathrm{B}$

FIGURE 1

Total counts of S. uvarum, H. uvarum and C. boidinii in 2008 (A) and 2009 (B). The stuck period in 2008 was from day 45 to day 184, while in 2009 it was from day 41 to day 48. Standard deviations are calculated from duplicate qPCR measurements.

cells $/ \mathrm{mL}$ at the end of the fermentation. From day 30 these counts were higher than those of $H$. uvarum. C. boidinii counts increased at the beginning of the fermentation until day 30, after which they decreased again. From day 49 these counts stayed constant at around $2.2 \times 10^{2}$ cells $/ \mathrm{mL}$.

\section{Determination of selected must contents \\ Glucose and fructose}

The sugar concentration in the grape must (Fig. 2A and 2B) was considerably higher in 2008 than in 2009 (glucose: 122 $\mathrm{g} / \mathrm{L}$ (2008) and $85 \mathrm{~g} / \mathrm{L}$ (2009); fructose: $119 \mathrm{~g} / \mathrm{L} \mathrm{(2008)} \mathrm{and}$ $78 \mathrm{~g} / \mathrm{L}(2009))$. After a slow metabolism of the sugars during the first days of the fermentation, the glucose and fructose concentrations decreased rapidly from day 20 in 2008 and day 10 in 2009. At a glucose concentration of $15 \mathrm{~g} / \mathrm{L}$ in 2008 and $3.2 \mathrm{~g} / \mathrm{L}$ in 2009 , and a fructose concentration of $44 \mathrm{~g} / \mathrm{L}$ in 2008 and $27 \mathrm{~g} / \mathrm{L}$ in 2009, the fermentation became stuck (day 45). By day 80 in 2008, two "identical" barrels were combined and this caused an increase in the sugar concentration.

An important factor regarding stuck fermentation is the glucose/fructose ratio. Stuck fermentation appeared at a glucose/fructose ratio of 0.34 in 2008 (Fig. 2C). The ratio increased to 0.5 after the combination of the two barrels and then remained constant during the stuck period. After the fermentation started again, it decreased rapidly to 0.07 . In 2009 , the glucose/fructose ratio was 0.12 when the fermentation became stuck. It did not change during the stuck period and then decreased to 0.08 at the end of the fermentation.

\section{Ethanol}

Ethanol was produced to a final concentration of $12.8 \%$ in 2008 and $11 \%$ in 2009 (data not shown). In 2008, a rapid increase in the ethanol concentration was observed from day 24 to day 45 . During the stuck period, the ethanol concentration remained stable. After the restart of the fermentation, the concentration increased quickly to $12.8 \%$ at the end of the fermentation. In 2009, the ethanol concentration at the beginning of the stuck period was $10 \%$ (day 41). As was observed in 2008, the concentration did not change during the stuck period. 


\section{pH and acetate}

The $\mathrm{pH}$ increased slowly from 3.01 at the beginning to 3.34 at the end of the fermentation in 2008, and from 3.12 to 3.25 in 2009. In 2008, acetate could be measured before the stuck period appeared. Its concentration changed from 0.11 to 0.25 $\mathrm{g} / \mathrm{L}$ from day 24 to the end of the fermentation (data not shown). In 2009, acetate was only detected after the stuck period (day 71) and increased to $0.33 \mathrm{~g} / \mathrm{L}$ at the end of the fermentation.

\section{DISCUSSION}

This study provides an overview of the succession of the culturable yeasts and bacteria in a spontaneously fermenting grape must which became stuck during the fermentation period. No special measures (e.g. the addition of starter cultures) were taken to restart the stuck fermentations at the winery concerned. The must stayed in the barrels until the fermentation was finished, which normally took months.

In general, the variety of organisms on the grapes and consequently in the must is influenced by the region and climate, the grape variety, the pressure from disease, the level of damage of the grapes and the vineyard practices (Bisson \& Joseph, 2009).

\section{Yeasts}

The fermentation started with the yeasts belonging to the genera Candida, Pichia, Hanseniaspora, Metschnikowia, Cryptococcus, Filobasidium and Rhodotorula, although the last three genera were not isolated in 2008. Either they were absent or their titre was too low for them to be detected in the grape must by serial dilutions and subsequent plating. The Basidiomycetes of the genera Cryptococcus and Rhodotorula are weak fermenters and known to appear on the grapes during the early stage of ripening, followed by the Ascomycetes of Hanseniaspora, Candida and Metschnikowia as dominant grape-surface yeast microbiota as the grapes ripen (Bisson $\&$ Joseph, 2009). Yeasts of these genera appearing at the beginning of the fermentation are normally repressed by Saccharomyces species, due to the lower sugar and higher alcohol concentration of progressive fermentation (Dittrich \& Grossmann, 2011). Interestingly, it was not $S$. cerevisiae (often isolated from musts), but $S$. uvarum, that was isolated in this study. This could be explained by the relatively low temperature of the wine cellar $\left(11\right.$ to $\left.13^{\circ} \mathrm{C}\right)$, since $S$. uvarum is more cryotolerant than $S$. cerevisiae (Eglinton et al., 2000). Earlier investigations of Riesling musts at this winery showed that $S$. uvarum and not $S$. cerevisiae was the main fermenting organism (data not shown).

S. uvarum was responsible for the main fermentation and its cell counts increased rapidly after the beginning of the fermentation. H. uvarum was present at higher cell counts ( $3.6 \times 10^{4}$ cells $/ \mathrm{mL}$ ) than $S$. uvarum at the beginning of the fermentation, but, from day 37 , the counts of $S$. uvarum were higher. Interestingly, H. uvarum was not detected by plating after day 45, but this species was detected with PCR until the end of the fermentation. Only viable cells are quantified with plating, but dead and viable cells are counted with qPCR. In addition, lower cell numbers can be detected with qPCR.

At the start of the stuck period, cell counts no longer increased. The S. uvarum and C. boidinii counts stayed
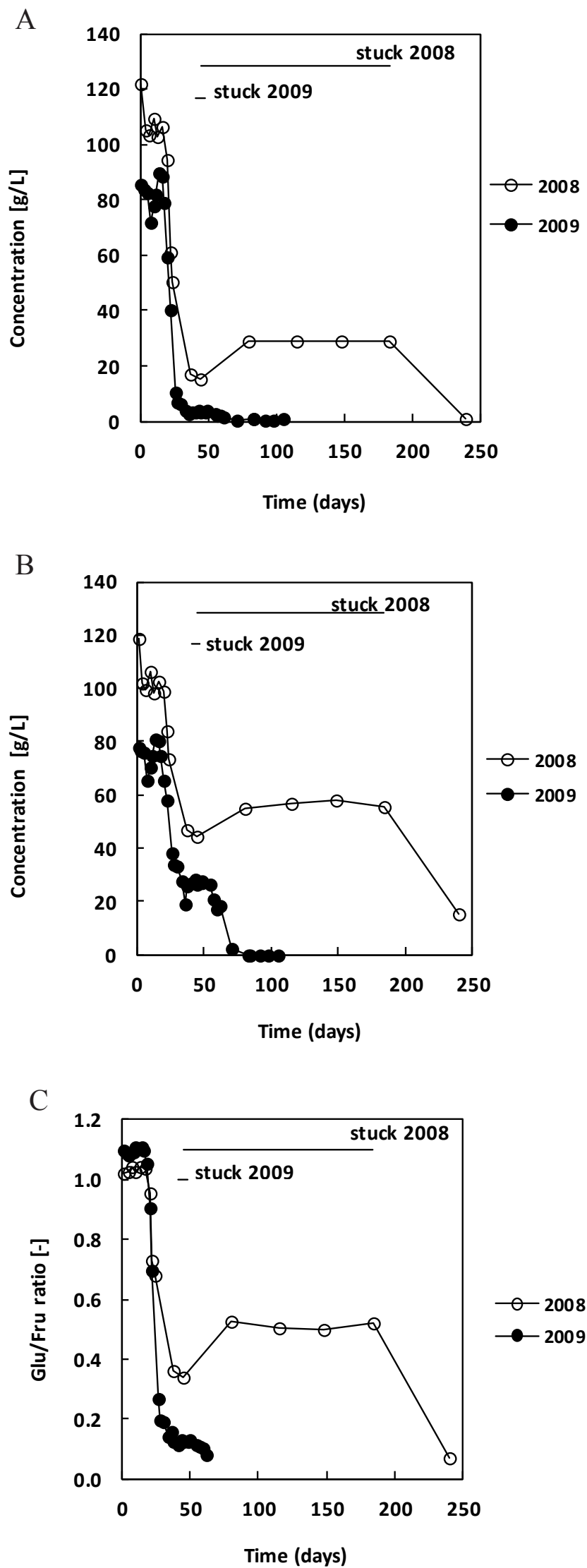

FIGURE 2

The glucose concentration (A), fructose concentration (B) and the glucose/fructose ratio (C) in Riesling must during the fermentation in 2008 (open symbols) and 2009 (closed symbols). The stuck period in 2008 was from day 45 to day 184 and in 2009 it was from day 41 to day 48. 
more or less constant, while $H$. uvarum counts decreased. A decrease in cell counts at the beginning of the stuck fermentation could be explained by sedimentation of the cells. Ascending gas bubbles of $\mathrm{CO}_{2}$ lead to a mixing of the must. When no $\mathrm{CO}_{2}$ is produced, the cells slowly sediment. By day 115, all the counts increased again, although the fermentation was still stuck (no visible $\mathrm{CO}_{2}$ production was detected at the top of the vessel).

A similar effect was observed in 2009. As in 2008, the highest counts at the beginning were for $H$. uvarum, while the counts of $S$. uvarum were low. The $S$. uvarum counts increased rapidly after the fermentation started, and were higher than $H$. uvarum counts from day 30 . In general, the cell counts of the three investigated organisms were lower in 2009 compared to 2008. This could be explained by the lower sugar concentrations in 2009, which will be discussed below. The counts of the three tested species decreased after the beginning of the stuck period and increased again thereafter (day 49).

Candida zemplinina is able to grow in must with a high sugar and a high ethanol concentration and at low temperatures. However, the temperature tolerance does not make this species a competitor of $S$. uvarum in must fermentations, since the ethanol concentration is less inhibitory to Saccharomyces species than to C. zemplinina (Sipiczki, 2003). This was also observed in the present study, since $C$. zemplinina was no longer isolated after 24 and 49 days in 2008 and 2009 respectively. Although most yeasts disappeared during the fermentation, some yeasts were isolated until the end of the fermentation, e.g. C. oleophila. This species is known for its lytic activity, as it produces cell wall-degrading enzymes like exo- $\beta$-1,3-glucanase, chitinase and protease (Bar-Shimon et al., 2004), which could play a role during stuck fermentation. In earlier studies, Candida spp. were shown to be able to complete the fermentation (Bisson \& Joseph, 2009).

\section{Bacteria}

In both years, different acetic acid bacteria could be isolated during almost the entire fermentation period. Acetic acid bacteria are strictly aerobic, although they can survive in the absence of oxygen (Bartowsky \& Henschke, 2008). They have a high tolerance of ethanol and oxidise it to acetic acid. They are often found in sugar-rich media, like must (Guillamón \& Mas, 2009). Growth of acetic acid bacteria has been observed in grape musts or during stuck fermentations when exposed to oxygen (Bartowsky \& Henschke, 2008). Interestingly, in both years Gluconobacter cerinus was isolated during the whole fermentation period. Its presence was also described in botrytised wines by Barbe et al. (2001). Lactic acid bacteria are known to be found in must and wine due to their tolerance of acidic conditions and ethanol. They can cause stuck fermentations by inhibiting Saccharomyces species (Huang et al., 1996), and can metabolise acids like tartrate, malate and citrate in must. Oenococcus oeni (isolated in 2008) in particular has a high tolerance of acid and ethanol and therefore is often used as a starter culture for the malolactic fermentation. Most of the lactic acid bacteria weakly grow or even disappear during the alcoholic fermentation (König \& Fröhlich, 2009). Oenococcus oeni was not isolated in 2009. Lactobacillus buchneri was only detected in 2009. In our study, Lactobacillus paracasei subsp. paracasei was isolated during the stuck period in 2008, and before as well as after the stuck period in 2009. This species has rarely been found in must or wine before (Dicks \& Endo, 2009), but it is possible that it is responsible for the malolactic fermentation together with the other lactic acid bacteria found in this study. The relationship between the presence of lactic and acetic acid bacteria and stuck fermentation has to be studied in more detail, together with their ability to inhibit the growth of $S$. uvarum.

The presence of Bacillus spp. and Paenibacillus spp. was surprising. Although Bacilli have been found in wines before (Gigi \& Vaughn, 1962), no studies about wine are known that describe the presence of the Bacillus and Paenibacillus species that were isolated in this investigation. However, probably only spores were present, since the vegetative cells were not able to grow in the must of our study (data not shown).

\section{Glucose/Fructose}

The sugar (glucose and fructose) concentration was higher in 2008 than in 2009. In this study, the shortest stuck period was observed in the must with the lower sugar concentration at the beginning of the stuck period. According to Gafner \& Schütz (1996), stuck fermentations are observed mainly when approximately $80 \%$ of the sugars have been converted. In our study, $86 \%$ and $81 \%$ of the sugars (glucose and fructose) were metabolised in 2008 and 2009 respectively, which is in accordance with Gafner and Schütz (1996). Although the glucose concentration did not change during the stuck period in 2009, it increased again at the beginning of the stuck period in 2008. This was due to the combination of two barrels. The second barrel apparently had a higher sugar concentration than the barrel we were investigating when they were combined. Although the sugar concentration did not change during the stuck period, cell counts of C. boidinii and S. uvarum increased during the second half of the stuck period. This could be caused by lysis of other yeast cells. Yeasts store glycogen in their cells (PérezTorrado et al., 2002). This could leak from dead cells and be converted into glucose, which can then be used by $C$. boidinii and $S$. uvarum for growth.

An important parameter to predict stuck fermentation is not only the sugar concentration itself, but also the ratio of glucose to fructose. In 2008 and 2009, the rate of metabolism of glucose and fructose was the same at the beginning of the fermentation, as is shown by the constant glucose/fructose ratio during the first two weeks. This can be explained by the presence of wild yeasts, which have the same preference for glucose and fructose (Dittrich \& Grossmann, 2011). After approximately three weeks, glucose was metabolised much faster than fructose, resulting in a rapid decrease in the glucose/fructose ratio to 0.34 and 0.12 in 2008 and 2009 respectively. As has been shown in many studies, Saccharomyces has a higher preference for glucose than for fructose, leading to a decrease in the glucose/fructose ratio (Gafner \& Schütz, 1996; Dittrich \& Grossmann, 2011). During the decrease of the glucose/fructose ratio, S. uvarum was isolated as the main fermenting organism, which could 
explain the faster metabolism of glucose compared to fructose. Gafner and Schütz (1996) showed that they could induce stuck fermentation by decreasing the glucose/fructose ratio below 0.1 . As long as the glucose/fructose ratio was above 0.5 , no stuck fermentation appeared. This was also observed in our study.

\section{Ethanol, pH, acetate}

It is interesting that the higher ethanol concentration at the beginning of the stuck formation in 2009 was associated with a shorter stuck period. However, the higher sugar concentrations in 2008 caused a higher final ethanol concentration, which was reached at the end of the fermentation.

The increase in the $\mathrm{pH}$ during the whole fermentation period indicated a net reduction in the acid concentration of the must. Acetic acid normally occurs in wine at a concentration ranging from 0.2 to $0.6 \mathrm{~g} / \mathrm{L}$ (Vilela-Moura et al., 2011). High acetate concentrations could cause stuck fermentation by inhibiting yeast growth (Alexandre \& Charpentier, 1998). Acetate can be produced by yeasts (e.g. Hanseniaspora, Candida, Pichia and Saccharomyces), lactic acid bacteria and acetic acid bacteria (Dittrich \& Grossman, 2011). Due to the presence of these organisms during the whole sampling period, it was decided to measure acetate concentrations. Since acetic acid did not reach concentrations higher than $0.33 \mathrm{~g} / \mathrm{L}$, it is expected that acetic acid was not the cause of the stuck fermentation.

In this study, the glucose/fructose ratio did not change during the stuck fermentation in 2008 after a constant value of 0.5 had been reached. As the value was still 0.5 at the moment the fermentation started again, and acetate did not reach limiting levels, other factors must play a role during the stuck period. One possibility could be an interaction between the organisms. Not much is known about these interactions. Hanseniaspora uvarum and Pichia kluyveri, but also species of Debaryomyces, Candida, Cryptococcus, Kluyveromyces and Metschnikowia, which inhibit the growth of Saccharomyces, have been described as killer yeasts (Radler et al., 1990; Vagnoli et al., 1993). Bar-Shimon et al. (2004) showed biocontrol of yeasts by a lytic activity of Candida oleophila. Pichia membranifaciens is known for its antifungal activity, probably due to the excretion of lytic enzymes such as chitinase and $\beta$-1,3-glucanase (Cao et al., 2010). It also produces a killer toxin against Saccharomyces cerevisiae (Santos et al., 2005). Interactions between the yeasts and bacteria isolated in the present investigation and S. uvarum have to be studied in detail. Currently, studies are being carried out to investigate interactions between S. uvarum and the isolated yeasts and bacteria. Specific primers for all the isolated yeasts and bacteria are being developed. When the mechanisms of these interactions are known, it will be easier to take precautions to avoid stuck fermentations without using starter cultures. This is preferred by some winemakers, as they believe the final wine will acquire a more specific sensory profile when the must is fermented spontaneously.

\section{CONCLUSION}

This study provides an overview of the succession of the microbiota during the stuck fermentation of a spontaneously fermenting must, together with cell counts and glucose/ fructose concentrations. Although $S$. uvarum was the main fermenting organism, other bacteria and yeasts could be isolated until the end of the fermentation. During the stuck period the microbiota changed. Other factors than the glucose or fructose concentration and the acetate concentration must play a role at the onset of the stuck period. It is expected that interactions between the different organisms could have an influence on the appearance of stuck fermentations.

\section{LITERATURE CITED}

Alexandre, H. \& Charpentier, C., 1998. Biochemical aspects of stuck and sluggish fermentation in grape must. J. Ind. Microbiol. Biotech. 20, 20-27.

Bae, S., Fleet, G. \& Heard, G., 2006. Lactic acid bacteria associated with wine grapes from several Australian vineyards. J. Appl. Microbiol. 100, 712-727.

Barbe, J., De Revel, G., Joyeux, A., Bertrand, A. \& Lonvaud-Funel, A., 2001. Role of botrytized grape microorganisms in $\mathrm{SO}_{2}$ binding phenomena. J. Appl. Microbiol. 90, 34-42.

Bar-Shimon, M., Yehuda, H., Cohen, L., Weiss, B., Kobeshnikov, A., Daus, A., Goldway, M., Wisniewski, M. \& Droby, S., 2004. Characterization of extracellular lytic enzymes produced by the yeast biocontrol agent Candida oleophila. Curr. Genet. 45, 140-148.

Bartowsky, E. \& Henschke, P., 2008. Acetic acid bacteria spoilage of bottled red wine. Int. J. Food Microbiol. 125, 60-70.

Berthels, N., Cordero Otero, R., Bauer, F., Pretorius I. \& Thevelein, J., 2008. Correlation between glucose/fructose discrepancy and hexokinase kinetic properties in different Saccharomyces cerevisiae wine yeast strains. Appl. Microbiol. Biotechnol. 77, 1083-1091.

Bisson, L. \& Joseph, C., 2009. Yeasts. In: König, H., Unden, G. \& Fröhlich, J. (eds). Microbiology of microorganisms on grapes, in must and in wine. Springer Verlag, Berlin. pp. $47-60$.

Cao, S., Yuan, Y., Hu, Z. \& Zheng, Y., 2010. Combination of Pichia membranifaciens and ammonium molybdate for controlling blue mould caused by Penicillium expansum in peach fruit. Int. J. Food Microbiol. 141, 173-176.

Cocolin, L., Bissson, L. \& Mills, D., 2000. Direct profiling of the yeast dynamics in wine fermentations. FEMS Microbiol. Lett. 189, 81-87.

Dicks, L. \& Endo, A., 2009. Taxonomic status of lactic acid bacteria in wine and key characteristics to differentiate species. S. Afr. J. Enol. Vitic. 30, 72-90.

Dittrich, H. \& Grossmann, M., 2011 (4th ed). Mikrobiologie des Weines. Verlag Eugen Ulmer GmbH \& Co, Stuttgart, Germany.

Du Toit, W. \& Lambrechts, M., 2002. The enumeration and identification of acetic bacteria from South African red wine fermentations. Int. J. Food. Microbiol. 74, 57-64.

Eglinton, M., McWilliam, S., Fogarty, M., Francis, L., Kwiatkowsli, M., Hoj P. \& Henschke, P., 2000. The effect of Saccharomyces bayanus-mediated fermentation on the chemical composition and aroma profile of Chardonnay wine. Aust. J. Grape Wine 6, 190-196.

Gafner, J. \& Schütz, M., 1996. Impact of glucose-fructose-ratio on stuck fermentations: practical experiences to restart stuck fermentations. Vitic. Enol. Sci. 51, 214-218.

Gigi, B. \& Vaughn, R., 1962. Characteristics of some bacteria associated with the spoilage of California dessert wines. Am. J. Enol. Vitic. 13, 20-31. 
Guillamón, J. \& Mas, A., 2009. Acetic acid bacteria. In: König, H., Unden, G. \& Fröhlich, J. (eds). Microbiology of microorganisms on grapes, in must and in wine. Springer Verlag, Berlin. pp. $31-46$

Hammes, W. \& Hertel, C., 2009. Genus I. Lactobacillus Beijerinck 1901, 212. In: De Vos, P., Garrity, G.M., Jones, D., Krieg, N.R., Ludwig W., Rainey, F.A., Schleifer K.-H. \& Whitman, W.B. (eds). Bergey's manual of systematic bacteriology, vol 3: The Firmicutes. Springer, New York. pp. $465-511$

Hierro, N., Esteve-Zarzoso, B., Mas, A. \& Guillamón, J., 2007. Monitoring of Saccharomyces and Hanseniaspora populations during alcoholic fermentation by real time quantitative PCR. FEMS Yeast Res. 7, 1340-1349.

Higuchi, R., Fockler, C., Dollinger G. \& Watson, R., 1993. Kinetic PCR analysis: real-time monitoring of DNA amplification reactions. Nat. Biotechnol. 11, 1025-1030.

Huang, Y., Edwards, C., Peterson J. \& Haag, K., 1996. Relationship between sluggish fermentations and the antagonism of yeast by lactic acid bacteria. Am. J. Enol. Vitic. 47, 1-10.

Kibbe, W.A., 2007. Oligocalc: an online oligonucleotide properties calculator. Nucleic Acids Res. 35, 43-46.

König, H. \& Fröhlich, J., 2009. Lactic acid bacteria. In: König, H., Unden, G. \& Fröhlich, J. (eds). Microbiology of microorganisms on grapes, in must and in wine. Springer Verlag, Berlin. pp. 3 - 29.

Lopandic, K., Tiefenbrunner, W., Gangl, H., Mandl, K., Berger, S., Leitner, G., Abd-Ellah, G., Querol, A., Gardner, R., Sterflinger, K. \& Prillinger, H., 2008. Molecular profiling of yeasts isolated during spontaneous fermentations of Austrian wines. FEMS Yeast Res. 8, 1063-1075.

Lopez, I., Ruiz-Larrea, F., Cocolin, L., Orr, E., Phister, T., Marshall, M., Van der Gheynst, J. \& Mills, D., 2003. Design and evaluation of PCR primers for analysis of bacterial populations in wine by denaturing gradient gel electrophoresis. Appl. Environ. Microbiol. 69, 6801-6807.

Malherbe, S., Bauer F. \& Du Toit, M., 2007. Understanding problem fermentations - A review. S. Afr. J. Enol. Vitic. 28, 169-186.

Mills, D., Johannsen E. \& Cocolin, L., 2002. Yeast diversity and persistence in Botrytis-affected wine fermentations. Appl. Environ. Microbiol. 68, 4884-4893.

Nisioutou, A., Spiropoulos A. \& Nychas, G., 2007. Yeast community structures and dynamics in healthy and Botrytis-affected grape must fermentations. Appl. Environ. Microbiol. 73, 6705-6713
Owczarzy, R., Tataurov, A., Wu, W., Manthey, J., McQuisten, K., Almabrazi, H., Pedersen, K., Lin, Y., Garretson, J., McEntaggart, N., Sailor, C., Dawson R. \& Peek, A., 2008. IDT SciTools: a suite for analysis and design of nucleic acid oligomers. Nucleic Acids. Res. 36, 163-169.

Pérez-Torrado, R., Gimeno-Alcaniz J. \& Matallana, E., 2002. Wine yeast strains engineered for glycogen overproduction display enhanced viability under glucose deprivation conditions. Appl. Environ. Microbiol. 68, 33393344 .

Pfannebecker, J., 2003. Entwicklung und Anwendung molekularbiologischer Methoden zur Art- und Stamm-Identifizierung pro- und eukaryotischer Organismen. Dissertation, Johannes-Gutenberg University Mainz, Germany.

Radler, F., Schmitt M. \& Meyer, B., 1990. Killer toxin of Hanseniaspora uvarum. Arch. Microbiol. 154, 175-178.

Renouf, V., Claisse O. \& Lonvaud-Funel, A., 2007. Inventory and monitoring of wine microbial consortia. Appl. Microbiol. Biotechnol. 75, 149-164.

Rozen, S. \& Skaletsky, H., 2000. Primer3 on the www for general users and for biologist programmers. Meth. Mol. Biol. 132, 365-386.

Santos, J., Del Mar Alvares, M., Mauro, M., Abrusci, C. \& Marquina, D., 2005. The transcriptional response of Saccharomyces cerevisiae to Pichia membranifaciens killer toxin. The J. Biol. Chem. 51, 41881-41892.

Sipiczki, M., 2003. Candida zemplinina sp. nov., an osmotolerant and psychrotolerant yeast that ferments sweet botrytized wines. Int. J. Sys. Evol. Microbiol. 53, 2079-2083.

Ultee, A., Souvatzi, N., Maniadi, K. \& König, H., 2004. Identification of the culturable and nonculturable bacterial population in ground water of a municipal water supply in Germany. J. Appl. Microbiol. 96, 560-568.

Vagnoli, P., Musmanno, R., Cresti, S., Di Maggio, T. \& Coratza, G., 1993. Occurrence of killer yeasts in spontaneous wine fermentations from the Tuscany region of Italy. Appl. Environ. Microbiol. 59, 4037-4043.

Vilela-Moura, A., Schuller, D., Mendes-Faia, A., Silva, D., Chaves, S., Sousa M. \& Côrte-Real, M., 2011. The impact of acetate metabolism on yeast fermentative performance and wine quality: reduction of volatile acidity of grape musts and wines. Appl. Microbiol. Biotechnol. 89, 271-280.

Ward, L. \& Timmins, M., 1999. Differentiation of Lactobacillus casei, Lactobacillus paracasei and Lactobacillus rhamnosus by polymerase chain reaction. Lett. Appl. Microbiol. 29, 90-92. 